\title{
Outcome Comparison of Transurethral Resection of the Prostate in Benign Prostatic Hyperplasia Patients in Karawang General Referral Hospital
}

\author{
Ramlan Halimi ${ }^{1}$, Achmad Rizky Herda Pratama ${ }^{2}$ \\ ${ }^{1}$ Departement of Urology, Faculty of Medicine University of Indonesia-Cipto Mangunkusumo General Hospital, Jakarta, Indonesia \\ 2 Department of Urology, Karawang General Referral Hospital, West Java, Indonesia
}

\section{ARTICLE INFO}

Received : 06 May 2019

Reviewed : 14 May 2019

Accepted : 01 August 2019

Keywords:

benign prostatic hyperplasia, outcome, TURP

\begin{abstract}
Background: Benign Prostatic Hyperplasia (BPH) is the most common pathological condition in man that causes Lower Urinary Tract Syndrome (LUTS). The most popular therapeutic modality for BPH is Transurethral Resection of Prostate (TURP). This study describes the TURP outcome in BPH patient with prostate size $>75$ grams compared to $<75$ grams in Karawang General Referral Hospital.
\end{abstract}

Methods: We performed a retrospective review of clinical outcome from BPH patient with LUTS who underwent TURP procedure between January 2017 - April 2018. Data was taken through patient medical records and processed descriptively to describe complications, quality of life, and clinical laboratory data. Qualitative data compared with Chi-Square test.

Results: During this study, we evaluated 40 patients, 20 patients with prostate size $>75$ grams (group 1) and 20 patients with prostate size $<75$ grams (group 2). Mean age in group 1 was 65.6 \pm 9.9 years and in group 2 was $65.3 \pm 10.2$ years. International Prostate Symptom Score (IPSS) after TURP between group 1 and group 2 showed a significant difference, while incomplete emptying was found mostly in group $2(p<0.05)$. There was no significant difference in Quality of Life Score between group 1 and group $2(p>0.05)$. From laboratory results, we found a reduction of hemoglobin in both groups with $p$-value $<0.05$ or no significant difference.

Conclusions: Transurethral Resection of Prostate (TURP) procedure for patient with prostate size $>75$ grams is safe and effective with lower complications and there is no significant difference compared to patient with prostate size $<75$ grams.

\author{
*Corresponding author: \\ Achmad Rizky Herda Pratama \\ Department of Urology, \\ Karawang General Referral Hospital, \\ West Java, Indonesia \\ herdapratama@gmail.com
}

The Transurethral Resection of Prostate (TURP) is the most popular therapeutic modality in $\mathrm{BPH}$ management and it is still the gold standard for $\mathrm{BPH}$ operative therapy $[1-7,23,28]$. There is no maximum limit of prostate size for this procedure in the literature, this depends on the specialist's experience in urology, speed of resection, and the tools used [7].

Usually, large-volume BPH management is performed with open surgery. Currently, it is still a debate on whether BPH management should be based on the size of the prostate volume. Some studies suggest that prostate size $>60$ grams should be performed in open surgery, while some other studies argued that open prostate surgery should be performed if the prostate size > 80 grams $[12-14,19]$. In this study, the limit used is 75 grams according to the Campbell-Wals urology [25]. We aim to find differences in TURP outcome between patients with prostate size $>75$ grams and $<75$ grams. 


\section{METHODS}

\section{Patients}

This research is a retrospective study by taking medical record data of BPH patients undergoing TURP surgery at Karawang Hospital from January 2017-April 2018. Patients' complaints in the form of LUTS and the most frequent surgical indications of acute urinary retention caused by $\mathrm{BPH}$ were collected. We operated these patients with noncontinuous mono-polar TURP with a maximum operating time of 60 minutes. All procedures performed in this study were in compliance with the guidelines of the Local Review Board and Ethical Committee and data were obtained with patient consent at the time of procedure/data collection.

Patients were grouped according to prostate size: group 1 consists of patients with prostate size $>75$ grams and group 2 consists of patients with prostate size $<75$ grams. Preoperative history includes urinary complaints and quality of life of patients (QoL) based on the International Prostate Symptom Score (IPSS), clinical examinations including digital rectal examination, complete blood examination, kidney function, electrolytes, and abdominal ultrasound to measure prostate size. One week after the patient was discharged, we assessed their urinary complaints and QoL based on IPSS. We evaluated IPSS and QoL by asking the patient seven questions for IPSS and one question for QoL. Interpretation of IPSS had three categories: mild (symptom score $\leq 7$ ), moderate (symptom score ranges 8-19), and severe (symptom score ranges 20-35). QoL showed how satisfied the patient was if the patient had to live with his current urinary symptoms for the rest of his life. QoL had range score between 0-6 (delighted-terrible).

Patients, who had LUTS complaints caused by bladder tumors, neurogenic bladder, and history of TURP surgery, were not included in this study. All patients received prophylactic antibiotics of 1 gram intravenous ceftriaxone. All TURPs were carried out by spinal anesthesia and done by senior residents (semester 8-10) who were already independent in doing TURP. Non-continuous Olympus working element and diathermy was set with 80-100 Watts for cutting and 40-50 watts for coagulation. During the TURP procedure, $5 \%$ dextrose fluid was used as irrigation. Resection started from the middle lobe of the prostate, then continued to the left lobe at 4-5 and continued at 1 o'clock, then continued to the right lobe of the prostate starting at 7-8 o'clock and forwarding at 11-12 o'clock. Control of bleeding was carried out to the maximum extent possible by coagulating the source of bleeding. The prostate chip was removed using Ellik evacuator, and finally, 22-24 Fr 3-way catheter was installed accompanied by irrigation using $0.9 \% \mathrm{NaCl} 80-100$ drops per minute.

Intra and postoperative complications (TURP syndrome, bleeding, blood clot retention, and urethral stricture) were all recorded in the patients' medical record. After the patient returned from the hospital, the control to the urology polyclinic was evaluated for voiding complaints and the quality of life of the patient. We presented Intra and postoperative complications (TURP syndrome, bleeding, blood clot retention, urethral stricture) as eventual complications. The postoperative laboratory was taken 24 hours after surgery.

\section{Statistical Analysis}

Data was taken through patients' medical records and then processed descriptively to compare pre- and post-operative complaints, complications, quality of life, laboratory (hemoglobin, hematocrit, leukocytes, and platelets) and the presence or absence of other surgery in patients. Independent T-test and Mann-Whitney $U$ test were performed to analyze the data. All statistical data were processed using SPSS 23.0. P-values of less than 0.05 were deemed statistically significant.

\section{RESULTS}

A total of 40 patients who underwent our TURP surgery were evaluated: 20 patients with prostate size of more than 75 grams (group 1) which met the inclusion criteria and 20 patients with prostate size less than 75 grams (group 2). The average age of patients in this study was $65.6 \pm 9.9$ years for group 1 and $65.3 \pm 10.2$ years for group 2. The average prostate size was 105.5 (75.7-263) grams for group 1 and 40.5 (20-70) grams for group 2. The incidence of acute urinary retention was 19 patients (95.0\%) in group 1 and 11 patients (55.0\%) in group 2 ( $p<0.05)$, meaning statistically significant.

The values of IPSS and QoL before surgery showed no statistically significant differences between group 1 and group 2 ( $p>0.05$ ) as shown in Table 1 and Table 2 . While postoperative IPSS values in the "incomplete emptying" section showed significant differences, where the complaints were more common in group 2 ( $p<0.05$ ). Postoperative QoL values also did not show significant differences between group 1 and group $2(p>0.05)$ as shown in Table 2 .

There was no intraoperative complication (TURP syndrome) in either group. Three patients had postoperative complications. One patient had blood clot retention and one patient had hematuria, occurred in group 2 on the first day after surgery. One patient had urethral stricture, occurred in group 2 after three months follow up. Comparison of intra- and postoperative in these two groups showed no statistical significance $(p>0.005)$

Table 4 shows the comparison of hemoglobin reduction between group 1 and group 2 . In group 1, the median value of hemoglobin reduction is 0.75 and in group 2 , the median value is 1.25 . There was a decrease of hemoglobin on each group, but the result did not show a statistically significant difference $(p>0.05)$. 
Table 1. Comparison of IPSS scores between group 1 and group 2 .

\begin{tabular}{|c|c|c|c|c|c|c|}
\hline & \multicolumn{3}{|c|}{ Before Surgery } & \multicolumn{3}{|c|}{ After surgery } \\
\hline & $\begin{array}{c}\text { Group 1 } \\
(>75 \text { gram N }=20)\end{array}$ & $\begin{array}{c}\text { Group 2 } \\
(>75 \text { gram } N=20)\end{array}$ & p-value & $\begin{array}{c}\text { Group 1 } \\
(>75 \text { gram N = 20) }\end{array}$ & $\begin{array}{c}\text { Group 2 } \\
(>75 \text { gram N }=20)\end{array}$ & $p$-value \\
\hline $\begin{array}{l}\text { How often have you had } \\
\text { the sensation of not emptying } \\
\text { your bladder? } \\
\text { (incomplete emptying)? }\end{array}$ & 4.05 & 4 & 0.653 & 0.9 & 0.04 & 0.036 \\
\hline $\begin{array}{l}\text { How often have you had } \\
\text { to urinate less than every } \\
\text { two hours? (frequency)? }\end{array}$ & 4.45 & 3.8 & 0.332 & 1.15 & 1.05 & 0.691 \\
\hline $\begin{array}{l}\text { How often have you found } \\
\text { you stopped and started } \\
\text { again several times when you } \\
\text { urinated? (intermittency)? }\end{array}$ & 3.9 & 3.85 & 0.875 & 0.55 & 0.95 & 0.169 \\
\hline $\begin{array}{l}\text { How often have you found it } \\
\text { difficult to postpone } \\
\text { urination? (urgency)? }\end{array}$ & 3.75 & 3.75 & 0.932 & 0.55 & 0.6 & 0.79 \\
\hline $\begin{array}{l}\text { How often have you had } \\
\text { a weak urinary stream? } \\
\text { (weak stream)? }\end{array}$ & 4.15 & 4.2 & 0.748 & 0.5 & 0.55 & 0.89 \\
\hline $\begin{array}{l}\text { How often have you had } \\
\text { to strain to start urination? } \\
\text { (straining)? }\end{array}$ & 3.75 & 4.1 & 0.301 & 0.35 & 0.45 & 0.921 \\
\hline $\begin{array}{l}\text { How many times did you } \\
\text { typically get up at night } \\
\text { to urinate? (nocturia)? }\end{array}$ & 4.6 & 4.75 & 0.603 & 0.85 & 0.5 & 0.276 \\
\hline
\end{tabular}

Table 2. Comparison of Quality of life (QoL) between group 1 and group 2

\begin{tabular}{lcccccc}
\hline & \multicolumn{3}{c}{ Before Surgery } & & \multicolumn{2}{c}{ After surgery } \\
\cline { 2 - 6 } & $\begin{array}{c}\text { Group 1 } \\
(>75 \text { gram N }=20)\end{array}$ & $\begin{array}{c}\text { Group 2 } \\
(>75 \text { gram N }=20)\end{array}$ & p-value & $\begin{array}{c}\text { Group 1 } \\
(>75 \text { gram N }=20)\end{array}$ & $\begin{array}{c}\text { Group 2 } \\
(>75 \text { gram N }=20)\end{array} \quad$ p-value \\
\hline $\begin{array}{l}\text { QoL before surgery } \\
\text { (mean, SD) }\end{array}$ & $5.46(0.795)$ & $5(0.605)$ & 0.06 & $1.45(1.095)$ & $1.4(1.146)$ & 0.864 \\
\hline
\end{tabular}

Table 3. Intra- and postoperative complications of surgery

\begin{tabular}{lccc}
\hline \multicolumn{1}{c}{ Outcomes } & $\begin{array}{c}\text { Group 1 } \\
(>75 \text { gram } \\
\mathrm{N}=20)\end{array}$ & $\begin{array}{c}\text { Group 2 } \\
(<75 \text { gram } \\
\mathrm{N}=20)\end{array}$ & p-value \\
\hline $\begin{array}{l}\text { Hematuria } \\
\begin{array}{l}\text { Blood clot } \\
\text { retention }\end{array}\end{array}$ & $0(0 \%)$ & $1(5 \%)$ & 1.000 \\
$\begin{array}{l}\text { Stricture urethra } \\
\text { TURP syndrome }\end{array}$ & $0(0 \%)$ & $1(5 \%)$ & 1.000 \\
\hline
\end{tabular}

Table 4. Intra- and postoperative complications of surgery

\begin{tabular}{lccc}
\hline Outcomes & $\begin{array}{c}\text { Group 1 } \\
(>75 \text { gram } \\
\mathrm{N}=20)\end{array}$ & $\begin{array}{c}\text { Group 2 } \\
(<75 \text { gram } \\
\mathrm{N}=20)\end{array}$ & p-value \\
\hline & & & \\
$\begin{array}{l}\text { Hemoglobin } \\
\text { reduction }\end{array}$ & 0.75 & 1,25 & \\
$\begin{array}{l}\text { median, } \\
\text { (min-max })\end{array}$ & $(-0.04-4.00)$ & $(-1.7-5.30)$ & 0.104 \\
\hline
\end{tabular}




\section{DISCUSSION}

The main objective of $\mathrm{BPH}$ surgical treatment modalities is to reduce patient complaints, reduce the number of complications, improve quality of life, improve urine flow and reduce the incidence of repeat surgery $[15,16]$. Transurethral Resection of Prostate (TURP) is the most commonly used operating modality, this action supersedes other operating modalities and is still the gold standard for BPH management [12]. More than $95 \%$ of $\mathrm{BPH}$ cases are treated with TURP operations with various medical indications including acute urinary retention, failed trial without catheter (TwoC), recurrent urinary tract infections, recurrent macroscopic haematuria, urinary tract stones, decreased renal function caused by BPH obstruction and pathological changes in the bladder and upper urinary tract $[7,17,24]$. For large-sized prostate (> 75 grams), open prostatectomy is still one of the options for therapeutic modalities, although the definition of "large" here is subjective and still debated, the procedure depends on expertise, experience, and speed of resection of operators [12].

There is always a risk of the possibility of perioperative complications in patients with large prostate size, such as intra and postoperative bleeding and TURP syndrome. But more advanced operating equipment, irrigation fluids, and surgical techniques caused a significant decrease in the number of complications, such as the incidence of TURP syndrome which is now below 1\% [12]. Early complications that can occur along with TURP can be in the form of bleeding that requires transfusion (0-9\%), TURP syndrome (0-5\%), AUR (0-13.3\%), blood clot retention (0-39\%), and urinary tract infections (0-22\%). Meanwhile, the perioperative mortality rate (first 30 days) was $0.1 \%$. In addition, long-term complications that can occur include urinary incontinence (2.2\%), bladder neck stenosis $(4.7 \%)$, urethral stricture $(3.8 \%)$, retrograde ejaculation (65.4\%), erectile dysfunction (6.5-14\%), urinary retention and UTI [7].

Open prostatectomy is the most invasive method of surgery with greater morbidity. Early complications that occur at the time of surgery were reported as much as $7-14 \%$ in the form of bleeding that requires transfusion [7,21]. Meanwhile, perioperative mortality (first 30 days) is below $0.25 \%$. Long-term complications can include bladder neck contractures, urethral stricture (6\%) and urinary incontinence $(10 \%)[7,26]$. Kadir Ceylan's research from the urology department of the University of Yuzuncu Yıl, Turkey, examined 320 patients who underwent open prostatectomy from January 2006December 2012, with short-term complications of $20.3 \%$ and long-term complications of $14.3 \%$. Short-term complications include blood clot retention (6.6\%), intraoperative bleeding (3.2\%), surgical wound infection $(4 \%)$, vesicocutaneous fistula $(4.7 \%)$, and repeat surgery due to blood clot retention (1,5\%). Long-term complications include urinary tract infections (7.5\%), epididymo-orchitis (3.1\%), urinary incontinence (0.9\%) and bladder neck contractures or urethral strictures (2.2\%) [31].

Our patients were male patients with an age range of $65.6 \pm 9.9$ years for group 1 and $65.3 \pm 10.2$ years for group 2. The average prostate size was 105.5 (75.7-263) grams for groups 1 and 40.5 (20-70) grams for group 2. Another study conducted by Joshi et al. [1] from the urology department of Dhulikhel HospitalKathmandu University Hospital, Dhulikhel, Kavre, Nepal, obtained a comparison of the patient's age was $71.8 \pm 6.9$ years for the group 1 and $68.2 \pm 12.7$ years for group 2 . The average prostate size was $88.8 \pm 8.7$ grams for group 1 and $40.3 \pm 11.8$ grams for group 2 . The incidence of acute urinary retention in our study was 19 patients (95.0\%) in group 1 and 11 patients $(55.0 \%)$ in group 2 with a value of $p<0.05$, which is different compared to data found in Joshi et al. [1] study which found the incidence of acute urinary retention in 11 patients (36\%) in group 1 and 10 patients $(28 \%)$ in group 2 with a value of $p>0.05$, meaning not statistically significant.

The values of IPSS before surgery in our study obtained a comparison of results that were not statistically significant, whereas in Joshi et al. [1] study, there were significant pre-operative IPSS results on the incomplete emptying parameters which occur in 30 patients in group 1 and 28 patients in group 2 with p-values < 0.05, while other IPSS parameters showed results that are in line with our research. Quality of life (QoL) values before surgery in our study were also not statistically different between group 1 and group 2, whereas Joshi et al. [1] study showed significant results, namely 4.26 in groups 1 and 3.22 in group 2 with $p$-values $<0.05$.

The IPSS values of incomplete emptying parameters showed 0.9 in groups 1 and 0.4 in group 2 with a p-value $<0.05$, whereas in Joshi et al. [1] researchers did not compare QoL after surgery. In our study, comparison of incomplete emptying between each group showed statistical difference in after surgery IPSS. Based on the score (0.9 vs 0.4 ) with $p$-value $<0.05$, it had statistical significance, but it had no clinical significance.

Postoperative complications in our study were blood clot retention (1 patient), hematuria (1 patient) and urethral stricture (1 patient) which all occurred in group 2, with no clinical significance compared to group 1 ( $p>0.05)$. Meanwhile, postoperative complications in Joshi et al. [1] study was TURP syndrome (2 patients in group 1) and urethral stricture (2 patients in group $2)$, with no statistical significance.

Nevertheless, the limitation of this study is the number of patient was too small. We should be extended to a larger population and longer time to follow up. 


\section{CONCLUSIONS}

In conclusion, TURP procedure for patient with prostate size $>75$ grams is safe and effective with lower complications, and there is no significant difference compared to patient with prostate size $<75$ grams.

\section{DECLARATIONS}

\section{Competing of Interest}

There is no conflict of interest in this study. This study was provided by the institution without any external funding from sponsors.

\section{Acknowledgment}

The authors would like to express our gratitude to everyone that contributed to the making of this paper.

\section{REFERENCES}

1. Joshi HN, de Jong IJ, Karmacharya RM, Shrestha B, Shrestha R. Outcomes of transurethral resection of the prostate in benign prostatic hyperplasia comparing prostate size of more than 80 grams to prostate size less than 80 grams. Kathmandu University Medical Journal. 2014;12: 163-7.

2. Roehrborn CG. Benign Prostatic Hyperplasia: Etiology, Pathophysiology, Epidemiology, and Natural History. In Wein AJ (eds) Campbell-Walsh Urology $11^{\text {th }}$. Elsevier; 2016. pp 2425-662.

3. Al-Hammouri F, Abu-Qamar A. Monopolar Transurethral resection of the big prostate, experience at Prince Hussein Bin Abdullah Urology Center. J Pak Med Assoc. 2011;61: 628-31.

4. Kallenberg F, Hossack TA, Woo HH. Long-term followup after electrocautery transurethral resection of the prostate for benign prostatic hyperplasia. Adv Urol. 2011;20: 1-6.

5. Palaniappan S, Kuo TL, Cheng CW, Foo KT. Early outcome of transurethral enucleation and resection of the prostate versus transurethral resection of the prostate. Singapore Med J. 2016;57(12): 676-680.

6. Madduri VK, Bera MK, Pal DK. Monopolar versus bipolar transurethral resection of prostate for benign prostatic hyperplasia: Operative outcomes and surgeon preferences, a real-world scenario. Urology Annals. 2016;8: 291-96.

7. Mochtar CA, Umbas R, Soebadi DM, Rasyid N, Noegroho BS, Poernomo BB et al. Panduan penatalaksanaan klinis pembesaran prostat jinak. Ikatan Ahli Urologi Indonesia (IAUI). 2015;2: 1-27.
8. Tang J, Yang J. Etiopathogenesis of benign prostatic hyperplasia. Ind J Urol.2009;25: 312-7.

9. Abrams P, Chpple C, Khoury S, Roehrborn C, de La Rosette J. International Scientific committee. Evaluation and treatment of lower urinary tract symptoms in older men. J Urol. 2009;81: 1779-87.

10. Djavan B, Nickel JC, De La Rosette J, Abrams P. The Urologist view of $\mathrm{BPH}$ progression: results of an international survey. Eur Urol. 2002;41: 490-6.

11. Berry SJ, Coffey DS, Walsh PC, Ewing LL. The development of human benign prostatic hyperplasia with age. J Urol. 1984;132: 474-9.

12. Yucel M, Aras B, Yalcinkaya S, Hatipoglu NK, Aras E. Conventional monopolar transurethral resection of prostate in patients with large prostate (>/- 80 grams). Cent European J Urol. 2013;66(3): 303-308.

13. Elssayed EO, Mansour MI, Eliman M. Clinical appraisal of TURP in Gezira Hospital for renal diseases and surgery. Global Journal of medical research surgeries and cardiovascular system. 2013;13: 13-7.

14. Olumi AF, Richie JP. Urologic Surgery. In: Townsend CR, Beauchamp RD, Evers BM, Mattox KL (editors). Sabiston Textbook of Surgery, 18th ed. Sunders Elsevier; 2008. pp 2251-2285.

15. Madersbacher S, Marberg $M$. Is the transurethral resection of prostate still justified? BJU Int. 1999;83: 227-37.

16. Madersbacher S, Lackner J, Brossner C, Rochlich M, Stancik I, Willinger M, et al. Prostate Study Group of the Austrian Society of Urology. Reoperation, myocardial Infarction and mortality after transurethral and open prostatectomy: a nation-wide, long-term analysis of 23,123 cases. Eur Urol. 2005;47: 499-504.

17. Mebust WK, Roizo R, Schroeder F, Villers A. Correlations between pathology, clinical symptoms and course of the disease. The International Consultation on Benign Prostatic HyperplasiaProceedings. Paris; 1991. pp 51-62.

18. May F, Hartung R. Surgical atlas. Transurethral resection of the prostate. BJU Int. 2006;98(4):921-34.

19. Fitzpatrick JM. Millin retropubic prostatectomy. In Hohenfellner R (eds) Advanced Urologic Surgery. Wiley-Blackwell; 2005. pp 139-41.

20. Kirby RS. Progressive development of benign prostatic hyperplasia. In; Kirby RS (eds) An atlas prostatic diseases $3^{\text {rd }}$ edition. London: CRC Press; 2003. pp 58-62.

21. Hinman F, Stempen PH. Anatomy and principles of excision of the prostate. In: Hinman Jr (eds) Atlas of Urologic Surgery $2^{\text {nd }}$ edition. Saunders; 2010. pp 412-64.

22. Stern JA, Fitzpatrick JM, McVary KT. Prostate anatomy and causative theories pathophysiology and natural history of benign prostatic hyperplasia. In: McVary KT (eds) Management of benign prostatic hypertrophy. New York: Humana Press; 2004. pp 1-19. 
23. Donahue TF, Costa JA. Transurethral needle ablation of the prostate. In: McVary KT (eds) Management of benign prostatic hypertrophy. New York: Humana Press; 2004. pp 97-108.

24. Foster $H E$, Jacobs $M$. Transurethral resection of the prostate. In: McVary KT (eds) Management of benign prostatic hypertrophy. New York: Humana Press; 2004. pp 163-93.

25. Kozlowski JM, Smith ND, Grayhack JT. Suprapubic transvesical prostatectomy and simple perineal prostatectomy for the treatment of benign prostatic hyperplasia. In: McVary KT (eds) Management of benign prostatic hypertrophy. New York: Humana Press; 2004. pp 221-62.

26. Connolly SS, Fitzpatrick JM. Complication of open prostate surgery. In: Loughlin KR (eds) Complications in urologic surgery and practice. London: CRC Press; 2007. pp 129-35.
27. Helfand BT, McVary KT. Complication of minimally invasive treatments for lower urinary tract symptoms secondary to benign prostatic hyperplasia. In: Loughlin KR (eds) Complications in urologic surgery and practice. London: CRC Press; 2007. pp 393-423.

28. Kursh ED. Evaluation and treatment of benign prostatic hyperplasia. In: Potts JM (eds) Essential Urology $1^{\text {st }}$ edition. Totowa NJ: Humana Press; 2004. pp 191-202.

29. Jacobsen SJ, Girman CJ, Lieber MM. Natural history of benign prostatic hyperplasia. Urology. 2001;58: 5-16.

30. Hegarty P, Fitzpatrick JM, Bruskewitz. Medical management - watchful waiting. In Kirby RS, McConnell JD, Fitzpatrick J, Roehrborn CG, Wyllie M, Boyle P (eds) Therapeutic treatment for benign prostatic hyperplasia. London: CRC Press; 2005. pp 1-9.

31. Ceylan K. Open prostatectomy the result of a series of 320 cases in rural area. Eur J Gen Med. 2006;3(1): 11-15. 